\title{
LIBERALISMO E FEMINISMO: IGUALDADE DE GÊNERO EM CAROLE PATEMAN E MARTHANUSSBAUM
}

\author{
Ingrid Cyfer
}

\begin{abstract}
RESUMO
O artigo discute a relação entre liberalismo e feminismo a partir de duas autoras feministas, Carole Pateman e Martha Nussbaum. Trata-se de uma questão importante para o feminismo, para o qual são fundamentais problemas associados às dicotomias público-privado e cultura-natureza - herdadas do liberalismo. Nesse sentido, discutimos as posições de Carole Pateman e Martha Nussbaum referentes a esses problemas. A escolha das autoras deveu-se ao fato de que ambas compartilham muitas premissas e conclusões, e por suas divergências situarem-se principalmente ao redor de problemas em que o feminismo é acrescentado ao liberalismo político. Assim sendo, fazer uma discussão entre as suas posições minimiza o risco de que a análise do debate não vá muito além das críticas que diversas teorias dirigem ao liberalismo, podendo funcionar, enfim, como uma boa porta de entrada para alguns dos pontos mais controversos da teoria feminista contemporânea. Nussbaum e Pateman parecem coincidir a respeito da concepção de igualdade de gênero. A crítica que ambas dirigem à relação entre natureza e cultura e ao formalismo da igualdade abstrata torna evidente que nenhuma delas pretende atribuir o poder ou a opressão da mulher a desígnios da natureza. Em ambas está muito claro que o que consideram relevante na organização de uma sociedade justa quanto ao gênero é a forma como uma sociedade valora as diferenças biológicas, bem como as implicações dessa valoração na distribuição de bens sociais. Nussbaum, porém, acredita que essa equação seja possivel dentro da teoria liberal, desde que esta seja submetida a transformações que eliminem deturpações teóricas decorrentes do conservadorismo dos primeiros filósofos liberais.
\end{abstract}

PALAVRAS-CHAVE: feminismo; teoria feminista; liberalismo politico; igualdade de gênero; natureza e cultura; público e privado.

\section{INTRODUÇÃO}

"Feminismo" é ao mesmo tempo um termo maldito e impreciso. Maldito porque é na maior parte dos casos associado à defesa de uma suposta superioridade feminina, que exprimiria o mesmo sexismo do discurso que inferioriza as mulheres. Outra crítica comum é a de que o feminismo seria cego às diferenças biológicas entre homens e mulheres devido a um inconformismo injustificado e imponderado em relação às diferenças naturais, moralmente neutras. Diz-se ainda que o discurso feminista vitimaria a mulher na medida em que responsabilizaria exclusivamente o homem pela condição subalterna feminina. E, finalmente, é bastante freqüente também associálo a discursos moralistas que, em nome da igualdade, reprimiriam a sexualidade de homens e mulheres ao identificar a sedução e a relação sexual como locus de discriminação, nos quais a mulher estaria reduzida à condição de objeto.
A maior parte dessas críticas poderia atingir facilmente muitos alvos feministas. No entanto, dificilmente abalariam uma significativa gama de movimentos e teorias que se denominam feministas e, se fizessem-no, isso seria devido à imprecisão do termo "feminista", que mascara as inúmeras nuances e divergências comportadas pelo conceito. A conseqüência dessa imprecisão é que as discussões acerca da igualdade entre homens e mulheres são freqüentemente deslegitimadas por críticas que tomam o feminismo por um termo unívoco. Diante disso, deve-se reconhecer que a adequação conceitual e mesmo estratégica da insistência no termo "feminismo" deve ser questionada.

Com Simone de Beauvoir e Gayle Rubin, o feminismo incorporou a idéia de que a identidade feminina não é uma simples decorrência da biologia, mas sim uma condição apreendida ao longo da vida na relação com o outro. Assim, as refle- 
xões acerca da igualdade de gênero passariam a considerar concepções de identidades construídas culturalmente, que estão além de uma essência inscrita na anatomia. É preciso reconhecer que não é exatamente isso que se observa em uma parcela do discurso feminista, que focaliza unicamente um dos pólos da relação de gênero (a mulher), e não na própria relação da qual emergem as identidades masculina e feminina.

Por outro lado, há razões para que o termo permaneça. Além de ser uma herança histórica dos movimentos e teorias pioneiros nessa discussão, é também muitas vezes o único adjetivo que unifica as inúmeras vertentes feministas. No campo da teoria política, há feminismos liberais, marxistas, pósmodernos, existencialistas, e outros tantos. Identificar aquilo que há em comum entre eles não é uma tarefa fácil, pois cada teoria irá propor seu próprio entendimento de discriminação de gênero, bem como suas próprias fórmulas para combatê-la.

O traço comum entre essas teorias não está em princípios éticos ou em uma concepção de política comum. A identidade entre elas restringese a seu objeto. Boa parte das teorias políticas qualificadas como feministas têm por objeto o estudo da igualdade de gênero, ou seja, são teorias que investigam em que homens e mulheres devem ser iguais, para que uma sociedade seja justa quanto ao gênero.

Neste artigo serão discutidas as posições de Carole Pateman e Martha Nussbaum acerca desse tema ${ }^{1}$. A escolha das autoras deveu-se ao fato de que ambas compartilham muitas premissas e conclusões; e por suas divergências situarem-se principalmente ao redor de problemas em que o feminismo é acrescentado ao liberalismo políti$\mathrm{co}^{2}$. Assim sendo, fazer uma discussão entre as suas posições minimiza o risco de que a análise

\footnotetext{
1 A intenção do artigo é reconstruir e confrontar as posições de Nussbaum e Pateman. No entanto, elas não dialogam diretamente. Nussbaum, porém, menciona Pateman como uma autora adversária em nota de rodapé, aliando-a a Allison Jaggar, sua interlocutora direta (NUSSBAUM, 1999, p. 384). Anne Phillips, em artigo em que discute o feminismo liberal de Nussbaum, também reconhece em Pateman uma tese que contesta a posição de Nussbaum (PHILLIPS, 2001).

2 Nussbaum e Pateman utilizam a expressão "liberalismo político", mas não lhe atribuem exatamente o mesmo sentido. Pateman, ao sustentar que o liberalismo é necessaria-
}

do debate não vá muito além das críticas que diversas teorias dirigem ao liberalismo, podendo funcionar, enfim, como uma boa porta de entrada para alguns dos pontos mais controversos da teoria feminista contemporânea.

\section{FEMINISMO E LIBERALISMO}

Um dos poucos pontos consensuais entre as teorias políticas feministas é o bordão o pessoal é político, ou seja, a idéia de que as circunstâncias pessoais são estruturadas por fatores públicos (PATEMAN, 1989). O sentido e a extensão que esse bordão assume em cada uma delas, porém, é bastante variável. As teorias liberais tenderão a restringi-lo, uma vez que terão de combinar essa idéia com a preservação do espaço privado, sob pena de comprometerem sua identidade liberal. As teorias não-liberais, por sua vez, têm geralmente menos problemas em conciliá-lo com sua matriz teórica; mas, de outro lado, dificilmente poderão renunciar totalmente à noção liberal de autonomia do sujeito, que tem sido palavra de ordem do movimento feminista desde o século XIX.

Disso decorre que toda teoria feminista, independentemente de como seja classificada, jamais reproduzirá fielmente a sua origem teórica. $\mathrm{O}$ feminismo apresenta tanto para teses que tendem para o coletivismo quanto para o individualismo, para o universalismo quanto para o relativismo, problemas que lhes obrigam a fazer concessões às teorias adversárias. Essas concessões, porém, não serão referentes às mesmas questões nem tampouco serão feitas em um mesmo grau. As variações e combinações são inúmeras, o que explica a impressionante ramificação das teorias políticas feministas contemporâneas (KYMLICKA, 2006).

Entretanto, ainda que as ramificações sejam muitas, o liberalismo político tem uma relação privilegiada com o discurso feminista, que desde sua origem incorporou muitos de seus conceitos e premissas. As primeiras feministas encontraram na dicotomia liberal público-privado o argumento

mente patriarcal, assume John Locke como seu principal interlocutor. Nussbaum, por sua vez, ao salientar as contribuições do liberalismo político para o feminismo inspirase no "liberalismo igualitário", especialmente o de Amartya Sen. Essa divergência explica em grande parte a oposição entre as posições de Nussbaum e Pateman, conforme se verá adiante. 
para salvaguardar um espaço em que a mulher pudesse gerir sua conduta sem a interferência estatal na distribuição de papéis sociais. Reivindicações feministas típicas como o direito ao aborto, ao trabalho, à liberdade sexual, entre outros, aparecem freqüentemente atreladas à noção de autonomia, entendida principalmente como não-intervenção estatal na esfera da privacidade do sujeito.

No entanto, os limites do liberalismo político para o feminismo tornar-se-iam evidentes já em fins do século XIX. Elizabeth Cady Stanton, uma das principais vozes do feminismo liberal da época, foi alvo de críticas por reivindicar direitos para as mulheres isolando-as do contexto que restringe seu acesso ao trabalho e à participação política (BRYSSON, 1992). Sem questionar a distribuição de tarefas e de poder na esfera doméstica, o feminismo liberal do século XIX encontrava suas próprias limitações.

Desde aquela época, a maior parte das críticas dirigidas ao feminismo liberal tem como alvo a dicotomia público-privado em sua versão clássica, com fundamento em Locke. Nessa vertente, a linha divisória separa a sociedade civil do Estado. A sociedade representa o espaço da liberdade pessoal, a esfera em que os indivíduos experimentariam a "independência perfeita", uma vez que ali estariam a salvo da coerção do Estado, restrita à esfera pública.

Além dessa, há ainda outra forma de distinguir o público do privado, segundo a qual os pólos opostos correspondem não à sociedade civil e ao Estado, mas ao social e ao pessoal. Na origem, essa foi uma distinção proposta pelo romantismo para se contrapor ao liberalismo, que não teria reservado nenhuma esfera para a intimidade. Os românticos afirmavam que mesmo a esfera social não libera o indivíduo de forças coercitivas, uma vez que as expectativas sociais constrangeriam os sujeitos a representarem papéis. O comportamento do indivíduo estaria, enfim, sob constante vigilância e julgamento também na esfera social. Os indivíduos, porém, diziam os românticos, precisam de tempo para si, precisam ter um espaço em que possam abandonar todos os papéis da vida civil, em que estejam protegidos do olhar e do julgamento do grupo (político e social) a que pertencem. A esse espaço chamaram de esfera pessoal ou íntima, na qual estariam incluídas apenas as relações de amizade e de amor (ROSENBLUM, 1987)
A reação de boa parte dos liberais diante do discurso romântico foi a de incorporá-lo ao seu projeto. A noção de intimidade foi traduzida pelos liberais como "direito à privacidade", cuja identificação com o liberalismo tornou-se intensa a ponto de ofuscar sua origem romântica (BENN \& GAUSS, 1999).

As duas versões da dicotomia público-privado são problemáticas para o feminismo. A primeira, como foi dito acima, porque assumiria que soluções meramente formais, como o direito ao voto, seriam medidas suficientes para emancipar as mulheres de papéis subordinados. A segunda, por sua vez, porque resguardaria da intervenção pública as relações amorosas, familiares e sexuais, que são os espaços em que a discriminação de gênero aparece mais intensamente. As teorias feministas, por mais diversas que possam ser suas concepções de igualdade, têm de lidar simultaneamente tanto com a demanda pela reserva de um espaço de não-interferência social e estatal nas escolhas e na conduta individual das mulheres, como com a demanda de intervenção estatal na esfera privada quando é preciso evitar ou coibir práticas sexistas de grupos sociais conservadores (NUSSBAUM, 1999).

As criminalizações da violência doméstica e, em particular, do estupro marital estão entre as discriminações de gênero que mais desafiam a dicotomia público-privado, em qualquer de suas versões. Afinal, mesmo na concepção mais restrita de privado do liberalismo de influência romântica, pode ser difícil justificar a intervenção estatal em relações conjugais que pertencem à esfera de intimidade (MACKINNON, 1987). De outro lado, a fusão do publico e do privado também apresenta problemas para o feminismo. Afinal, como defender, por exemplo, a liberdade sexual feminina ou o direito ao aborto se não houver limites à interferência estatal no controle do comportamento individual?

Como se vê, os debates acerca do feminismo convergem para a dicotomia público-privado. Pateman chega a afirmar que o feminismo definese por essa discussão (PATEMAN, 1989), uma vez que a posição acerca daquela dicotomia exprimiria a concepção de igualdade que fundamenta uma teoria feminista. Quanto mais abstrata e formalista a concepção de igualdade, mais intensa será a separação entre o público e o privado; ao passo que, quanto mais focada na igualdade material, mais essa separação terá de ser atenuada. 
As teorias de Pateman e de Nussbaum, respectivamente, não estão em pólos diametralmente opostos em relação a essa questão. Nenhuma delas defende a separação ou a fusão total entre o público e o privado. No entanto, enquanto Nussbaum sustenta que é possível e necessário flexibilizar essa dicotomia sem comprometer idéias basilares do liberalismo, como individualidade e autonomia, Pateman acredita que o liberalismo não sobrevive sem que essa oposição permaneça forte, pois é precisamente nesse aspecto teórico que o liberalismo revelaria seu comprometimento histórico e ideológico com o conservadorismo patriarcal.

\section{A CRÍTICA DE PATEMAN À DICOTOMIA PÚBLICO-PRIVADO}

Embora reconheça que o feminismo tenha nascido com o discurso liberal e que o ideal de liberdade e igualdade abstratas tenha sido a tônica do movimento feminista por décadas, Pateman sustenta que o liberalismo e o patriarcalismo sempre estiveram mutuamente implicados. Segundo ela, as teorias sobre o contrato social jamais estendeu sua doutrina da liberdade e da igualdade universal às mulheres (idem). As características atribuídas ao "ser humano universal" eram características masculinas. Apesar das marcantes diferenças entre os contratualistas clássicos, a origem do político em todos eles é um contrato social do qual as mulheres são excluídas. A racionalidade e a liberdade não são atributos universais quanto ao gênero. Por isso, diz ela, o contrato social é também um contrato sexual (PATEMAN, 1993, p. 69ss.).

Pateman sustenta que a sociedade civil, que resulta do contrato social, está ancorada no patriarcalismo. É a sujeição da mulher que garante as condições para a fruição da liberdade no espaço público pelo homem. A "liberdade civil depende do direito patriarcal” (idem, p. 19). Em Locke, afirma Pateman, o fundamento patriarcal da divisão entre os direito político e o patriarcal aparece claramente. Ao definir a especificidade do poder político, Locke assumiria que o caráter hierárquico da relação entre marido e mulher não seria político, mas natural (PATEMAN, 1989). Isso fica claro quando ele distingue o poder político do poder do "pai de família" no âmbito doméstico, afirmando que na esfera política o poder seria convencional e, por isso, passível de ser exercido sobre adultos; enquanto que o poder no âmbito doméstico subordinaria os indivíduos às ordens do chefe de família. Os indivíduos a que Locke se refere não são apenas as crianças, uma vez que ele assume que o papel dos maridos em relação às mulheres está incluído em formas não políticas de poder. A conseqüência disso seria a exclusão da mulher da esfera pública, pois aquele que é subordinado por natureza não poderia participar do espaço que é governado por princípios que universalizam a liberdade e a igualdade. De outro lado, essa divisão implica também a exclusão da aplicabilidade desses princípios à única esfera destinada à mulher, a doméstica (idem).

Pateman observa ainda que a esfera doméstica não está incluída no conceito de público nem no conceito de privado (social) de Locke. A sociedade civil teria abstraído o ambiente doméstico, tornando-o invisível. Sinal disso estaria nas expressões "sociedade e estado", "economia e política", "social e político" que muitas vezes são utilizadas como equivalentes de "privado e público", respectivamente. O espaço familiar, onde se constroem e reproduzem as identidades de gênero, permaneceria esquecido na discussão teórica liberal (OKIN, 1989).

Para Pateman, esse esquecimento não foi questionado pelo feminismo liberal. As sufragistas do século XIX teriam confrontado apenas a idéia de que o espaço privado não seria a única esfera a que a mulher deveria ter acesso. Não teriam, portanto, chegado a questionar o espaço doméstico como o lugar feminino por excelência (PATEMAN, 1989). Stuart Mill poderia ser alvo dessa mesma crítica. $\mathrm{O}$ autor reivindicou reformas legais com o objetivo de emancipar as mulheres do jugo de seus maridos, e contribuiu para forjar o bordão feminista "o pessoal é político" na medida em que utiliza termos políticos quando qualifica a condição da mulher no espaço doméstico. Palavras como "escravas", "igualdade", "liberdade" e "justiça" foram trazidas para o âmbito doméstico por Mill. No entanto, o autor sustenta que mesmo após as reformas legais que equiparassem maridos e esposas, o casamento deveria continuar representando uma carreira para a mulher (idem; MILL, 1970).

Com essa idéia, afirma Pateman, Mill deixa intacta a divisão de trabalho na esfera doméstica e revela uma concepção de igualdade de gênero meramente formal, porque parece acreditar na suficiência da supressão de entraves legais para garantir o acesso feminino à esfera pública. A di- 
visão do trabalho doméstico não é objeto de crítica de Mill. Ao contrário, o autor afirma que a divisão tradicional é um acordo que convém tanto a homens quanto a mulheres, sugerindo a justificação dessa repartição de tarefas na natureza (idem; idem).

A íntima relação entre o privado e o natural está, segundo Pateman, na base da interconexão entre liberalismo e patriarcalismo, e aparece mesmo em liberais considerados feministas, como Stuart Mill. O público e o privado podem, portanto, ser também denominados espaço da cultura e da natureza, respectivamente, mas qualquer que seja a nomenclatura utilizada, o espaço masculino será o primeiro, e o feminino, o segundo.

A identificação do feminino com a natureza teria três conseqüências. A primeira seria a desvalorização das atividades consideradas femininas. Isso porque teríamos herdado dos gregos o valor da superação da existência meramente natural. A cultura seria a expressão do potencial criativo dos seres humanos, que os singulariza e distingue dos animais (PATEMAN, 1989). A segunda conseqüência, por sua vez, consiste em considerar essa dicotomia inquestionável e imutável. Se for a natureza que distribuiu as tarefas referentes à criação dos filhos, por exemplo, os seres humanos não teriam muito a fazer a não ser adaptar à vida em sociedade a distinção entre tarefas (e identidades) femininas e masculinas. Finalmente, a terceira conseqüência diz respeito à abstração histórica implícita na dicotomia público-privado. Ao considerá-la uma imposição da natureza, além de imutável e amoral, a divisão entre o público e o privado será assumida também como descontextualizada. Assim, fundamentada na natureza, a dicotomia obscureceria a relação entre liberalismo e patriarcalismo, e a relação de ambos com o capitalismo. Este último teria incorporado a dicotomia público-privado à medida que se desenvolvia, concentrando tanto a teoria quanto a prática políticas na esfera pública e civil, marginalizando a esfera doméstica. $\mathrm{O}$ capitalismo não teria, portanto, definido apenas uma divisão de classes, mas também uma divisão sexual com a qual se relaciona a primeira.

A divisão sexual do trabalho afastaria as mulheres do mercado ou inseri-las-ia ali em condições desvantajosas, mas o liberalismo seria incapaz de diagnosticar como desigualdade de gênero a desigualdade nas condições de inserção da mu- lher no mercado de trabalho, uma vez que a gênese dessa desigualdade estaria na divisão de trabalho no âmbito doméstico, que para a teoria liberal não é política ou socialmente relevante. $\mathrm{P}$ e 1 a mesma razão, o liberalismo tampouco forneceria uma resposta para o problema da precariedade dos trabalhos das mulheres que, por necessidade, estão no mercado de trabalho, como é o caso das mulheres da classe trabalhadora. Estas sempre tiveram de trabalhar, mas a elas foram destinadas apenas tarefas mal remuneradas, desvalorizadas e que muitas vezes são meras reproduções das atividades domésticas, tal como ocorre com os empregos de babá, faxineira, empregada doméstica etc. Portanto, no que se refere à condição feminina, a dicotomia público-privado teria a conseqüência de, a um só tempo, confinar a mulher ao espaço doméstico, subordiná-la economicamente ao homem e/ou empobrecê-la, restringir sua participação política e atribuir tudo isso a razões imutáveis de ordem metafísica (idem).

Em síntese, a conclusão de Pateman é a de que o liberalismo está estruturalmente ligado ao patriarcalismo e, por isso, a dicotomia públicoprivado seria uma armadilha para o movimento feminista. Armadilha porque à primeira vista serve-lhe aos propósitos da emancipação, mas logo se revela um modelo de perpetuação da rigorosa divisão sexual dos papéis sociais. O sujeito liberal, ou seja, o indivíduo autônomo, singular e capaz de possuir propriedades em nome próprio não seria, portanto, um sujeito universal (do ponto de vista do gênero), pois o argumento conservador e patriarcal a respeito da natureza da mulher teria sido incorporado pelo liberalismo em um de seus elementos mais estruturais, a separação entre as esferas pública e doméstica. Por isso, um feminismo liberal padeceria de inconsistências incontornáveis, uma vez que, aceitando a dicotomia público-privado, não poderia evitar seu caráter patriarcal e, aceitando o bordão feminista "o pessoal é político", não poderia conciliá-lo com o liberalismo (OKIN, 1992).

A identificação entre liberalismo e patriarcalismo que Pateman sustenta pode ser atestada em Locke e na maior parte dos autores liberais clássicos, até mesmo em Stuart Mill. No entanto, isso não é uma particularidade do liberalismo político. Os autores clássicos no melhor dos casos calaramse e no pior deles opuseram-se abertamente à idéia da igualdade de gênero. A teoria política feminista não é uma construção dos filósofos clássicos, mas 
uma interpretação de suas teorias para tomá-las como fundamento da igualdade de gênero (idem).

Pateman tem razão quando denuncia as implicações do liberalismo clássico na discriminação de gênero. No entanto, isso ainda não é razão suficiente para afastar o liberalismo da fundamentação da igualdade de gênero. Sem avançar para além de Locke, ou mesmo de Mill, dificilmente o liberalismo serviria à fundamentação de qualquer relação de igualdade. O formalismo liberal já foi há muito denunciado e, dentro do liberalismo contemporâneo, foram propostas fórmulas para a sua superação.

O feminismo liberal percorreu esse mesmo caminho, de modo que a maior parte dessas teorias está atualmente bem além de Locke. Para descartar o liberalismo como fundamento da igualdade de gênero é preciso, portanto, analisar se o que essas teorias contemporâneas acrescentam à sua matriz teórica é suficiente para desfigurá-la por completo ou não.

$\mathrm{O}$ argumento de Pateman de que o feminismo não se compatibiliza com a separação estanque entre o público e o privado é corroborado pela maior parte das teorias feministas liberais contemporâneas. Entretanto, enquanto as feministas liberais flexibilizam a relação entre o público e o privado, Pateman sustenta que o liberalismo não sobrevive sem essa oposição fortemente marcada, tanto por razões teóricas quanto ideológicas. Isso não significa, porém, que Pateman defenda a fusão do público e do privado. Sua idéia é a de que a crítica feminista adote uma perspectiva dialética da vida social, de modo a evitar tanto a separação estanque entre o público e o privado, quanto o risco de o bordão "o pessoal é político" confundir público e privado a ponto de não restar nenhuma dimensão da vida humana preservada da exposição pública. A autora não sugere outra teoria política em substituição ao liberalismo. Sua conclusão é a de que "o feminismo ainda aguarda a sua filosofia” (PATEMAN, 1989).

\section{A DICOTOMIA PÚBLICO-PRIVADO NO FEMINISMO LIBERAL DE MARTHA NUSSBAUM}

Nussbaum reconhece que as críticas de Pateman sejam válidas para alguns autores liberais, e que algumas delas deveriam ser incorporadas ao liberalismo político feminista. No entanto, sua posição é a de que elas não seriam suficientes para ruir a sustentação e a consistência do feminismo liberal. Segundo ela, o liberalismo precisa ser modificado pela crítica feminista, mas essas mudanças não o descaracterizariam. Ao contrário, elas torná-lo-iam mais consistente com seus próprios fundamentos. Para justificar essa posição, Nussbaum primeiramente define os contornos do liberalismo em que apóia sua concepção de igualdade de gênero, para então formular sua defesa do liberalismo como fundamento da igualdade de gênero (NUSSBAUM, 1999).

Da teoria liberal (em particular a kantiana), a autora extrai duas idéias centrais. A primeira é a da igual dignidade entre os seres humanos e a segunda, o poder de escolha moral do indivíduo entendido como habilidade de planejar uma vida de acordo com sua própria avaliação de fins. Dessas idéias decorreriam compromissos políticos que a autora julga serem indispensáveis a uma teoria feminista. O primeiro é o de não tornar diferenças moralmente irrelevantes fontes sistemáticas de hierarquia social. Assim, o liberalismo seria necessariamente crítico da discriminação racial, de classe, de gênero, ao sistema de castas etc. Além disso, o liberalismo opor-se-ia também a formas de política cooperativas ou organicamente organizadas. A finalidade da política liberal seria o bemcomum, universal, sem privilegiar determinados grupos em detrimento de outros. Esse bem-comum, porém, jamais poderia perder de vista que o fim último da política é o bem-estar dos indivíduos. Por fim, a política liberal estaria comprometida com a tolerância e com a diversidade, no sentido de que não poderia se voltar a uma forma particular de bem, fosse ela religiosa ou laica (idem).

Nesse arcabouço, a autora identifica aquilo que considera o conceito liberal mais valioso para o feminismo: a autonomia do indivíduo. Tomando o indivíduo como unidade básica do pensamento político, a teoria liberal opor-se-ia à idéia de que o indivíduo funde-se à coletividade, seja ela a comunidade política, seu grupo social ou mesmo a família.

O liberalismo político, porém, tem sido objeto de inúmeras críticas de teorias feministas influentes, como a de Pateman. As críticas de Pateman comentadas no item anterior referem-se a duas questões centrais: a relação entre natureza e cultura e o caráter abstrato da igualdade liberal. A primeira questão seria tratada pelo liberalismo de 
forma a justificar em bases amorais e apolíticas a distribuição de papéis no âmbito privado e público e, dessa forma, torná-la imutável; enquanto que a segunda cavaria um fosso entre a igualdade formal e as hierarquias e desigualdades sociais, de modo a afastá-las do campo de visão e ação das políticas liberais.

As posições de Pateman e Nussbaum são muito semelhantes no que se refere ao questionamento da origem natural da distribuição de papéis. Em ambas as autoras encontram-se críticas tanto ao discurso conservador tradicional (antifeminista), quanto a teorias feministas essencialistas, que defendem uma espécie de "direito à identidade feminina". A valoração dos atributos femininos "naturais" é a característica mais central do chamado feminismo essencialista. Esses atributos são freqüentemente relacionados à maternidade, entendida como a experiência que define o feminino. Os hormônios são também assumidos como fatores determinantes do comportamento da mulher. A carência de testosterona diminuiria sua agressividade e tornaria seu desejo sexual mais domesticável; ao passo que o estrogênio torná-laia propensa a assumir cuidados com crianças, a ser mais emotiva e naturalmente inclinada ao pacifismo (NUSSBAUM, 1997).

A idéia de que os hormônios determinam o comportamento maternal (que aqui equivale a feminino) baseia-se no aumento das taxas de estrogênio no período pós-parto, que a prepararia para assumir os cuidados de seu filho. Assim, as quantidades maiores de estrogênio nas mulheres (ao longo da vida) moldariam o comportamento feminino, dotando-o dos atributos necessários para a maternidade, ou seja, tornando-o mais terno do que agressivo (idem).

Em relação a essa questão, Nussbaum observa que as implicações do efetivo aumento das taxas de estrogênio no período pós-parto são interpretadas por essas teorias com um viés simplista e ideológico. Afinal, o comportamento maternal também inclui a agressividade, que ora é dirigida a possíveis agressores de seus filhos, ora é dirigida a seus próprios filhos ${ }^{3}$. Há muito já foi reconhecido, tanto científica quanto juridicamente, que o

\footnotetext{
3 O Direito brasileiro, por exemplo, considera o estado puerperal como um atenuante no crime em que a mãe mata seu fillho (infanticídio).
}

período pós-parto pode gerar emoções confusas e conflitantes, que incluem a depressão, o ódio, a agressividade e também a ternura e o amor.

Embora o discurso tradicional e o feminismo essencialista sustentem-se na mesma fundamentação biológica dos comportamentos humanos, a conseqüência política de ambos é distinta. O primeiro conduz à marcada dicotomia entre público e privado com todas as implicações éticas e políticas apontadas por Pateman. Já o segundo justifica discursos que consideram que a igualdade de gênero depende de que as diferenças naturais sejam eliminadas. Firestone, uma das feministas radicais mais influentes, chega a sustentar que a igualdade de gênero requer que a reprodução natural seja substituída pela artificial, de modo a abolir a gravidez e, com isso, as desigualdades de gênero que dela decorreriam.

As críticas de Pateman e Nussbaum acerca da fundamentação natural das identidades do feminino e do masculino convergem para os mesmos pontos. Ambas sustentam que o feminismo essencialista reproduz a idéia tradicional de que a subordinação da mulher é decretada pela natureza. Ambas as autoras estão de acordo com a idéia de que a tradução da dicotomia público-privado em cultural-natural revela um traço sexista do liberalismo político tradicional e também de algumas vertentes do feminismo. No entanto, tanto Nussbaum quanto Pateman rejeitam também a idéia de que as características biológicas sejam irrelevantes na definição das identidades sexuais. Em ambas, está expressamente presente a idéia de que biologia, embora não determine comportamentos, cumpre um papel na delimitação do feminino e do masculino, colocando limites na designação do que seria característico de cada um dessas representações.

Portanto, a identidade de gênero nessas autoras seria resultante da interação entre as dimensões biológica e cultural do ser humano. Disso decorre que o feminismo em Pateman e Nussbaum não fará reivindicações de reconhecimento de identidades nem tampouco de desconstrução do feminino ou do masculino (NUSSBAUM, 1997; PATEMAN, 1989). Em ambas o conceito de igualdade de gênero aplica-se à valoração dessas identidades e às implicações dessa valoração na distribuição de oportunidades entre homens e mulheres. Essas oportunidades incluem a realização pessoal, a possibilidade de planejar a própria vida, a 
participação política e o acesso ao trabalho sem custos adicionados em razão da identidade de gênero. No entanto, Pateman sustenta que o formalismo da igualdade liberal compromete-o com políticas indiferentes às desigualdades sociais, especialmente àquelas que decorrem da distribuição de poder no espaço doméstico.

Nussbaum também parece estar de acordo com Pateman neste ponto. Ela admite que é necessário ir além da igualdade abstrata para garantir a igualdade de gênero. Os estatutos antidiscriminação e as decisões judiciais neles baseados teriam se mostrado insuficientes para evitar e combater a restrição de oportunidades das mulheres em diversos setores da vida. Embora tenham efetivamente promovido o acesso da mulher a esferas que lhe eram proibidas, não teriam levado em conta que a facilidade desse acesso vê-se afetada pela interconexão entre a distribuição de tarefas no espaço doméstico e público. Se no campo do trabalho, por exemplo, determinadas funções impuserem exigências que são mais facilmente adequadas a pessoas que não são as principais responsáveis pelos cuidados de crianças em idade pré-escolar, a divisão sexual de tarefas no âmbito doméstico será determinante na competição pela vaga de trabalho, ainda que formalmente não seja imposta nenhuma restrição quanto ao sexo (NUSSBAUM, 1999; MACKINNON, 1987).

Entretanto, sua visão crítica da igualdade abstrata não se estende ao liberalismo em todas as suas versões. Nussbaum não estabelece uma relação automática ou necessária entre ambos, e cita concepções de igualdade de liberais igualitários como Amartya Sen e Rawls, nas quais está presente a idéia de que a igualdade de oportunidades exige pré-requisitos materiais, e que esses prérequisitos materiais devem variar conforme a posição real dos sujeitos na sociedade.

Em síntese, Nussbaum e Pateman estão de acordo quanto às implicações sexistas da dicotomia público-privado na qual estão implícitas tanto a fundamentação biológica da identidade sexual, quanto a igualdade abstrata. No entanto, elas divergem no que se refere à possibilidade de esse problema ser superado dentro do liberalismo. Enquanto Pateman considera que o feminismo não é compatível com a dicotomia público-privado, e, portanto, com o liberalismo, Nussbaum considera que o feminismo não pode prescindir de conceitos - chave liberais chave como a autonomia e a individualidade. A questão central desse debate, portanto, diz respeito à possibilidade de ir-se além da dicotomia liberal e ainda assim preservar a autonomia e a individualidade.

A concepção de individualismo que Nussbaum tem em mente sugere que a dicotomia públicoprivado seja traduzida como esfera pública e esfera da intimidade. Isso porque Nussbaum defende a substituição da idéia da dicotomia pela da interdependência, o que suporia uma esfera privada mais reduzida do que a esfera social de Locke. A idéia de interdependência difere da dicotomia exatamente na definição da divisória entre o público e o privado. Ambas exigem a preservação de uma esfera de não intervenção estatal, mas a noção de interdependência traz para o debate público as desigualdades no interior de associações civis que em Locke estariam a salvo da ingerência pública.

Os pontos comuns entre Nussbaum e Pateman revelam que a primeira corrobora as críticas de Pateman à dicotomia liberal concebida por Locke. Portanto, para analisar a divergência entre ambas acerca da relação entre a dicotomia público-privado e o feminismo, deve-se, avaliar se as críticas de Pateman estender-se-iam também à versão da dicotomia público-privado de influência romântica, ou seja, se a separação entre intimidade e social também tornaria invisíveis as assimetrias de poder no domínio doméstico.

O conceito de intimidade ou privacidade, como foi dito, amplia a esfera de intervenção do Estado. Todas as associações formais com outras pessoas, ao invés de serem localizadas na "esfera da liberdade", como em Locke, são consideradas públicas. A esfera da intimidade, porém, imporia uma barreira à regulação e ao controle da conduta do indivíduo. Nesse arranjo seria, enfim, evitada a fusão entre o público e o privado ao mesmo tempo em que se validaria a submissão das associações civis à regulação pública.

Entretanto, como foi dito anteriormente, mesmo essa versão da dicotomia público-privado apresenta problemas para o feminismo. Se as relações amorosas e de amizade forem totalmente impermeáveis à intervenção estatal, o estupro marital e a violência doméstica não poderiam ser criminalizados, pois isso poderia ser entendido como uma violação da privacidade. Kymlicka relata que o "direito à privacidade" na Suprema Corte dos Estados Unidos foi inicialmente celebrado pelo 
feminismo, mas que, posteriormente, o próprio movimento feminista denunciaria esse direito como uma justificativa para a negligência do Estado na proteção dos direitos das mulheres (KYMLICKA, 2006).

A primeira decisão embasada no direito à privacidade é de 1965 (caso Griswold contra Connecticut). Neste caso, discutiu-se uma lei que negava o acesso de mulheres casadas a meios anticoncepcionais. $\mathrm{O}$ tribunal decidiu que essa lei seria nula por ferir o direito à privacidade, pois a decisão de ter filhos ou não seria exclusiva do casal. Em decisões posteriores, tornou-se evidente, porém, que a proteção "das decisões do casal" da intervenção estatal aprofundou a divisão entre o público e o privado, despolitizando as desigualdades existentes nas relações intrafamiliares (MACKINNON, 1987). O direito à privacidade terminou, enfim, sendo uma barreira que protege as famílias do "teste da justiça pública" (KYMLICKA, 2006).

A interpretação do direito à privacidade como privacidade conjugal tem por base uma concepção coletivista da família. A família substitui o indivíduo como unidade básica do pensamento político. $\mathrm{O}$ sujeito do direito à privacidade, portanto, foi o casal, e não o indivíduo; a autonomia familiar substituiu a autonomia individual. Segundo Kymlicka, a concepção coletivista (familiar) de privacidade não encontra fundamento na teoria liberal, mas sim em idéias pré-liberais a respeito da naturalidade da família tradicional. A proteção da família em nome do direito à privacidade teria sido conseqüência da adoção da linguagem liberal da privacidade pelos "protetores da domesticidade" (idem). Assim, a medida adequada para combater desigualdades de gênero no âmbito familiar não estaria em abandonar o discurso liberal. Ao contrário, seria preciso aprofundá-lo até finalmente dissociar o direito à privacidade da "autonomia familiar", retomando o indivíduo como o núcleo fundamental.

Nussbaum parece entender a dicotomia privado-público (de influência romântica) de forma muito semelhante à de Kymlicka, vendo ali um potencial para justificar a politização das relações familiares. Isso fica claro quando a autora afirma que os liberais clássicos teriam se revelado pouco liberais quando conceberam o espaço doméstico como uma esfera em que a mulher desaparece como unidade. Por isso, diz Nussbaum, a teoria feminista teria de ser ainda mais liberal do que o liberalismo clássico, que teria servido ao patriarcalismo por razões unicamente ideológicas e não por limitações teóricas (NUSSBAUM, 1999).

Em síntese, a idéia fundamental de Nussbaum é a de que o feminismo deve aprofundar a noção de autonomia e de individualismo, e deve fazê-lo com as ferramentas teóricas que o liberalismo fornece. Contra essa idéia levantam-se inúmeras teses. Uma das críticas mais contundentes refere-se justamente à idéia de que a autonomia individual como bem-social fundamental traz implicitamente dois problemas para as teorias que se pretendem igualitárias: o egoísmo psicológico e o solipsismo político.

O egoísmo psicológico consiste na caracterização do sujeito como alguém que age motivado somente pelo auto-interesse. Esse sujeito não seria capaz de ocupar-se do interesse dos demais membros do grupo. Não existiria entre os seres humanos qualquer empatia ou sentido de solidariedade (JAGGAR, 1983). Nussbaum concorda que isso poderia ser dito das teses de Hobbes e Bentham, mas afirma que não funciona para inúmeras outras teorias liberais que costumam ser objeto dessa mesma crítica. Segundo ela, Amartya Sen e Rawls teriam de ser excluídos desse grupo, já que em ambos está explicitamente presente a idéia de vinculação entre indivíduos. Em Sen isso fica claro quando critica o utilitarismo por subestimar a importância da empatia e do compromisso como motivos da ação, enquanto que em Rawls essa mesma idéia fica clara com a caracterização dos sujeitos na posição original, que devem assumir a perspectiva de $\operatorname{todos}^{4}$ (NUSSBAUM, 1999).

Mesmo o utilitarismo e o kantismo, mais freqüente e facilmente associados a essa crítica, não poderiam ser acusados de egoísmo psicológico. Em defesa do utilitarismo, Nussbaum salienta que a maximização da utilidade de todos requer grandes sacrifícios individuais e, em favor de Kant, a autora sustenta o fato de que a imperfeição dos deveres de benevolência é decorrente do fato de os sujeitos tenderem a privilegiar as pessoas mais próximas e queridas, em prejuízo de um

\footnotetext{
4 Nussbaum cita como exemplo o budismo que, mesmo sem considerar o sujeito como uma unidade destacada dos demais, considera o indivíduo auto-suficiente a ponto de poder ser indiferente a fatos (NUSSBAUM, 1999).
} 
universalismo humanista, que somente a razão poderia fundamentar.

O solipsismo político, por sua vez, relacionase à suposição de que os indivíduos seriam autosuficientes. Nussbaum, porém, observa que essa idéia não é necessariamente vinculada ao individualismo. Além disso, ela acrescenta que mesmo que a psicologia do liberalismo considerasse o indivíduo auto-suficiente, essa seria uma aposta normativa e não uma descrição da realidade.

O significado do individualismo no liberalismo, enfim, seria o de que a pessoa não se funde à coletividade ainda que faça parte dela. Nussbaum salienta, porém, que isso não implicaria numa concepção "atomista" de sujeito, que desconsideraria os laços que unem as pessoas, mas apenas que a distribuição justa de recursos e oportunidades deve levar em conta a condição de cada pessoa individualmente.

Entendido dessa forma, Nussbaum conclui que o individualismo liberal representa um importante instrumento do feminismo, uma vez que a individuação do sujeito confronta a idéia de que a mulher confunda-se com a unidade familiar e que, por isso, seu valor estaria condicionado apenas à sua contribuição enquanto reprodutoras e "cuidadoras" (caregivers), ou seja, condicionado à representação das personagens com a qual a família tradicional define-a.

Apesar de a individualidade entendida como separação (separateness) funcionar para contestar a identificação do espaço privado com o lugar feminino por excelência, ela apresenta também limitações significativas para o feminismo. Conforme observa Anne Phillips, a individualidade em Nussbaum é pensada isoladamente do contexto social da qual ela emerge. A separação de cada indivíduo, diz Phillips, é algo mais complexo do que reconhecer que temos mentes e corpos individuais (PHILLIPS, 2001, p. 254).

A ênfase na separação ("separateness") reforça a idéia que Pateman insistentemente contesta: a interpretação da autonomia como liberdade de escolha. Referindo-se a Locke, Pateman afirma que essa liberdade está diretamente ligada à idéia de propriedade, mais precisamente a ser "proprietário de si mesmo". Isso significa que ser livre é ser o único a ter direitos sobre si, é ser livre para fazer e definir seu modo e seu plano de vida. É, enfim, ser livre para fazer escolhas (PATEMAN, 1993, p. 88; PHILLIPS, 2001, p. 254).
Para o liberalismo a capacidade de fazer escolhas é central. Por isso, a junção entre o feminismo e o liberalismo pode conduzir à idéia de que o gênero é também uma escolha. A tentativa de Nussbaum de desnaturalizar a identidade feminina e a masculina sugere que o gênero é contingente porque podemos escolhê-lo. Mas essa idéia, conforme salienta Phillips, negligencia as limitações que nossa condição social impõe à nossa possibilidade de escolher nossas posições e papéis na sociedade em que vivemos (PHILLIPS, 2001, p. 256). Grande parte da crítica feminista ao liberalismo ataca justamente esse ponto. Ainda que o feminismo mais recente tenha insistido na idéia de que o corpo não determina o gênero, isso não significa dizer que o corpo não importa. Ao contrário, para o feminismo o corpo é um contexto e esse contexto cumpre um papel decisivo na definição de quem somos. Nosso corpo não é um invólucro do núcleo de nosso self. Ele também é parte constitutiva dele. Além do mais, mesmo que pudéssemos distanciar-nos de nosso corpo, não poderíamos evitar que os "outros" continuassem associando-nos a ele Nosso corpo é um importante aspecto do contexto em que a identidade de gênero é formada. Esse contexto, por sua vez, não é nossa propriedade. Nossa identidade social não é uma invenção ou uma escolha totalmente nossa. O gênero, enfim, não está em nossas mãos para dispormos dele ou a respeito dele como quisermos. Confiar nisso, diz Phillips, não é apenas ingênuo, é perigoso. Afinal, a centralidade da autonomia na teoria de Nussbaum minimiza as pressões sociais que limitam nossas escolhas. Essa minimização, por sua vez, sugere que qualquer condição que não seja fruto de uma livre-escolha é um fracasso e, ainda mais grave, sugere também que nos casos em que haveria essa livre-escolha, nós somos totalmente responsáveis pelo que vier a ocorrer. Enfim, a força da autonomia na teoria de Nussbaum, apesar de suas tentativas de afastar-se do racionalismo moderno, traz novamente à tona a ficção do agente abstrato e racional, um agente que a própria Nussbaum admite ser concebido a partir de valores identificados com o masculino (idem; NUSSBAUM, 1999, p. 71). Confiar em nossa capacidade de assumir o controle total sobre nossa vida é uma ilusão que pode ser perigosa. Para Phillips, Nussbaum falha ao colocar a autonomia como a questão central da igualdade de gênero porque isso minimiza as pressões sociais que limitam nossas escolhas. A auto- 
nomia está diretamente ligada à responsabilidade. Por isso, não levar devidamente em conta a força dessas pressões sugere que qualquer situação que não resulte de uma livre-escolha é um sinal de fracasso pelo qual somos responsáveis (PHILLIPS, 2001, p. 257).

\section{CONCLUSÕES}

O liberalismo abarca diversas posições políticas que muitas vezes fundamentam regimes profundamente distintos entre si. Essa pluralidade, como já foi salientado anteriormente, é também característica das teorias feministas, num grau ainda maior. Assim, para pensar o potencial do liberalismo na fundamentação do feminismo, é preciso identificar tanto o núcleo do liberalismo quanto o da concepção de igualdade que se toma como ponto de partida em uma teoria política feminista.

Nussbaum e Pateman parecem coincidir a respeito da concepção de igualdade de gênero. A crítica que ambas dirigem à relação entre natureza $\mathrm{e}$ cultura e ao formalismo da igualdade abstrata torna evidente que nenhuma delas pretende atribuir o poder ou a opressão da mulher a desígnios da natureza. Em ambas está muito claro que o que consideram relevante na organização de uma sociedade justa quanto ao gênero é a forma como uma sociedade valora as diferenças biológicas, bem como as implicações dessa valoração na distribuição de bens sociais. Quanto à igualdade abstrata, os argumentos também são os mesmos. Apesar de definir-se como liberal, Nussbaum está de acordo com Pateman acerca do curto alcance da igualdade abstrata no combate a desigualdades sociais.

Dessa base comum, resultam concepções semelhantes sobre a relação entre público e privado. A idéia de Nussbaum de que uma teoria feminista deva considerá-los interdependentes (e não opostos) em muito se assemelha à relação entre o público e o privado defendida por Pateman. Em outras palavras: tanto Pateman quanto Nussbaum entendem que o feminismo precisa tornar a esfera privada permeável à intervenção pública sem sacrificar a individualidade e a intimidade.

Nussbaum, porém, acredita que essa equação seja possível dentro da teoria liberal, desde que esta seja submetida a transformações que eliminem deturpações teóricas decorrentes do conservadorismo dos primeiros filósofos liberais. A autora sustenta, ainda, que insistir no liberalismo (modificado pela crítica feminista) é indispensável para o feminismo, pois este não sobrevive sem a concepção de autonomia e individualidade liberais. Pateman, por sua vez, embora não acredite que a consistência da teoria liberal sobreviva às modificações exigidas pelo feminismo, tampouco parece abrir mão da idéia de autonomia do indivíduo.

As divergências entre Nussbaum e Pateman desaguam, enfim, não tanto no potencial do liberalismo para o feminismo já que, quando criticam ou defendem o liberalismo, elas referem-se a uma tradição filosófica muito ampla privilegiando autores distintos como interlocutores. O ponto central aqui parece estar, sim, no modo em que cada uma delas entende a interdependência entre o público e o privado. Mas essa concepção de interdependência não é devidamente explicitada por nenhuma delas.

Nesse aspecto, a contribuição de Hannah Pitikin pode sugerir algumas combinações importantes entre os argumentos e preocupações de Nussbaum e Pateman. Pitikin sustenta que o público e o privado relacionam-se porque as questões que atingem a esfera pública somente o fazem porque afetam os indivíduos em suas vidas cotidianas na esfera privada. As demandas e insatisfações da dona de casa, por exemplo, são vividas como uma experiência individual e excepcional somente até que cada dona de casa perceba que sua situação é compartilhada por outras mulheres. Nesse momento, as questões individuais, sentidas na concretude da vida privada, tomam uma forma coletiva e podem aspirar ao status de questão de interesse público (PITKIN, 1981, p. 348).

Os argumentos de Nussbaum e Pateman sugerem que elas subscreveriam essa relação entre o público e o privado. Isso indica que, apesar dos contrastes de suas respectivas posições acerca do liberalismo e da autonomia, suas concepções de política estão bem mais próximas. Por isso, o caminho para o livre-trânsito das mulheres do espaço privado para o público em condições de igualdade com os homens parece estar antes numa reflexão acerca da concepção de política do que da de autonomia. E para isso, Pateman parece ser um melhor guia do que Nussbaum. 
Ingrid Cyfer (ingridcy@gmail.com) é Doutora em Ciência Política pela Universidade de São Paulo, USP.

\section{REFERÊNCIAS BIBLIOGRÁFICAS}

BENN, S. \& GAUSS, G. (eds.). 1983. Public and Private in Social Life. New York: St. Martin.

BRYSSON, V. 1992. Feminist Political Theory. London: Macmillan.

JAGGAR, A. 1983. Feminist Politics and Human Nature. Totowa: Rowman and Allanheld.

KYMLICKA, W. 2006. Filosofia política contemporânea. São Paulo: M. Fontes.

MACKINNON, C. 1987. Feminism Unmodified: Discourses on Life and Law. Cambridge, Mass.: Harvard University.

MILL, S. 1970. The Subjection of Women. In: ROSSI, A. (ed.). Essays on Sex Equality. Chicago: University of Chicago.

NUSSABUM, M. 1997. Construction of Love, Desire and Care. In: ESTLUND, D. M. \& NUSSBAUM, M. C. (eds.). Sex, Preference, and the Family: Essays on Law and Nature. New York: Oxford University.

1999. Sex and Social Justice. Oxford: Oxford University.
OKIN, S.1989. Justice, Gender, and the Family. Chicago: University of Chicago.

.1992. Women in Western Political Thought. Princeton: Princeton University.

PATEMAN, C. 1989. The Disorder of Women. Stanford: Stanford University.

1993. O contrato sexual. Rio de Janeiro: Paz e Terra.

PHILLIPS, A. 2001. Feminism and Liberalism Revisited: Has Martha Nussbaum Got It Right? Constellations, New York, v. 8, n. 2, p. 249266. Disponível em: http:// www.newschool.edu/uploadedFiles/TCDS/ Democracy_and_Diversity_Institutes/ Phillips_Feminism\%20and\%20Liberalism.pdf. Acesso em: 24.abr.2010.

PITKIN, H. 1981. Justice: On Relating Private and Public. Political Theory, London, v. 9, n. 3, p. 327-352, Aug.

ROSENBLUM, N. 1987. Another Liberalism: Romanticism and the Reconstruction of Liberal Thought. Cambridge, Mass.: Harvard University. 


\section{LIBERALISM AND FEMINISM: GENDER EQUALITY IN CAROLE PATEMAN AND MARTHA NUSSBAUM}

\section{Ingrid Cyfer}

This article discusses the relationship between liberalism and feminism through the work of two feminist scholars, Carole Pateman and Martha Nussbaum. This is an important issue for feminism, and one in which the problems associated with public-private and nature-culture dichotomies, inherited from liberalism, are fundamental. In this regard, we will discuss Carole Pateman and Martha Nussbaum's positions on the matter. Our choice of authors is due to the fact that both share many of same premises and conclusions, and because their divergences are located primarily around problems in which feminism is "added on" to political liberalism. Thus, in carrying out a discussion through both positions, we minimize the risk that the analysis of the debate move little beyond the critique that numerous theories have directed toward liberalism, and offer what can be a fruitful entry into one of the most controversial points in contemporary feminist theory. Nussbaum and Pateman seem to coincide regarding their conception of gender equality. In the criticism that both of them direct toward the nature-culture relationship and to the formalism of abstract equality, it becomes evident that neither seeks to attribute either power or the oppression of women to nature's designs. In both authors, it is very clear that what they consider relevant for the organization of a just society in terms of gender is the way in which a society places value on biological differences and what implications this has for the distribution of social goods. Nussbaum, however, believes that this equation can be dealt with within liberal theory, as long as it is subjected to changes which free it from theoretical problems linked to the conservative stance of the first liberal philosophers.

KEYWORDS: feminism; feminist theory; political liberalism; gender equality; nature and culture; public and private. 


\section{LIBÉRALISME ET FÉMINISME: ÉGALITÉ DE GENRE EN CAROLE PATEMAN ET MARTHA NUSSBAUM}

Ingrid Cyfer

L'article discute la relation entre le libéralisme et le féminisme à partir de deux auteurs féministes, Carole Pateman et Martha Nussbaum. Il s'agit d'une question importante pour le féminisme, pour lequel ce sont des problèmes fondamentaux associés aux dichotomies publiques et privés, culture et nature - héritées du libéralisme. Dans ce sens, nous discutons les positions de Carole Pateman et Martha Nussbaum qui font réference à ces problèmes. Le choix des auteurs est due au fait que toutes les deux partagent beaucoup d'hypothèses et des conclusions, et aussi car leurs différences se situent principalement autour de problèmes où le féminisme est ajouté au libéralisme politique. Ainsi, faire une discussion entre leurs positions, minimise le risque de que l'analyse du débat n'aille pas plus loin que les critiques lesquelles plusieurs théories dirigent au libéralisme, pouvant fonctionner, enfin, comme une bonne porte d'entrée pour quelques uns des points les plus controversés de la théorie féministe contemporaine. Nussbaum et Pateman semblent coïncider par rapport à la conception de l'égalité de genre. La critique que toutes les deux dirigent à la relation entre la nature et la culture et au formalisme de l'égalité abstraite, rend évident que aucune des deux a l'intention d'attribuer le pouvoir ou l'oppression de la femme aux objectifs de la nature. Chez toutes les deux, il est très clair que ce que c'est consideré pertinent dans l'organization d'une société juste par rapport au genre, c'est la forme dont une société valorise les différences biologiques, tout comme les implications de cette valorisation dans la distribution de biens sociaux. Mais, Nussbaum, croit que cette équation est possible dans la théorie libérale, tandis que celle-ci doit être soumise à des transformations qui éliminent des déformations théoriques qui suivent le conservatisme des premiers philosophes libéraux.

MOTS-CLES: féminisme, théorie féministe; libéralisme politique; égalité de genre; nature et culture; publique; privé. 